\title{
Antitumor efficacy of BAFF-R targeting CAR T cells manufactured under clinic-ready conditions
}

\author{
Zhenyuan Dong $^{1} \cdot$ Wesley A. Cheng $^{1} \cdot$ D. Lynne Smith ${ }^{1} \cdot$ Brian Huang $^{1} \cdot$ Tiantian Zhang $^{1} \cdot$ Wen-Chung Chang ${ }^{2}$. \\ Xiuli Wang ${ }^{2} \cdot$ Stephen J. Forman ${ }^{2} \cdot$ Larry W. Kwak $^{1} \cdot$ Hong Qin ${ }^{1} \mathbb{C}$
}

Received: 6 April 2020 / Accepted: 16 May 2020 / Published online: 25 May 2020

(c) The Author(s) 2020

\begin{abstract}
B-cell malignancies can potentially be cured by CD19 chimeric antigen receptor (CAR) T-cell therapy. Although clinical response rates can be up to $93 \%$ in acute lymphoblastic leukemia, treatment-related antigen loss and lack of therapeutic persistence contribute to disease relapse. These shortcomings of current CAR T-cell therapy indicate the need for biologically relevant target selection and for improving the efficacy and persistence of the CAR T cells, which we have addressed by developing a novel B-cell activating factor receptor (BAFF-R) CAR T-cell therapy with improved therapeutic persistence. BAFF-R is a B-cell survival receptor and highly expressed in B-cell malignancies. We developed a prototype CAR T cell that efficiently and specifically eliminated BAFF-R expressing human B-cell tumors in several xenogeneic mouse models, including models of CD19 antigen loss. We proceeded with translational development and validation of BAFF-R CAR T cells produced under current good manufacturing practices (cGMP). cGMP-grade BAFF-R CAR T cells underwent in vitro and in vivo validation in established models to confirm that the potency and efficacy of our original research modeling was replicated. Food and Drug Administration required release testing was performed to ensure our BAFF-R CAR T cells meet specifications for new drug products. Completing and exceeding these requirements, the data fully support the initiation of a first-in-human Phase 1 trial for BAFF-R-positive relapsed/refractory (r/r) B-ALL.
\end{abstract}

Keywords CAR T cell therapy · Acute lymphoblastic leukemia · GMP production · BAFF-R

\section{Introduction}

Chimeric antigen receptor (CAR) T-cell therapy has matured with the recent Food and Drug Administration (FDA) approval of CD19 CAR T cells marking a new era in cancer immunotherapy. This has curative potential for patients with B-cell malignancies, particularly acute lymphoblastic

Electronic supplementary material The online version of this article (https://doi.org/10.1007/s00262-020-02614-8) contains supplementary material, which is available to authorized users.

Hong Qin

hoqin@coh.org

1 Toni Stephenson Lymphoma Center, Department of Hematology and Hematopoietic Cell Transplantation, Beckman Research Institute of City of Hope, Duarte, CA 91010, USA

2 Center for CAR T Cell Therapy, Department of Hematology and Hematopoietic Cell Transplantation, Beckman Research Institute of City of Hope, Duarte, CA 91010, USA leukemia (ALL) where response (CR) rates of $62-93 \%$ were observed [1]. Encouraging results have also been seen in recent clinical trials in non-Hodgkin lymphoma (NHL) patients (CR 23-55\%) [2]. However, the potential of CD19 CAR $\mathrm{T}$ cells to treat $\mathrm{B}$-cell malignancies is tempered by treatment-related antigen loss and lack of therapeutic persistence that results in disease relapse [3-5]. These shortcomings of current CAR T-cell therapy indicate the need for biologically relevant target selection and for improving the efficacy and persistence of the CAR T cells.

In order to address this need, we have developed a novel B-cell activating factor receptor (BAFF-R) CAR T cell with overall improved therapeutic persistence [6]. BAFF-R is a well-studied B-cell survival receptor that is also highly expressed in B-cell malignancies [7-9]. We have described the development of a specific, high affinity humanized monoclonal antibody against natively expressed BAFF-R, which has limited off-target effects [10]. This was used to develop a prototype CAR T cell capable of efficiently and specifically eliminating BAFF-R expressing human B-cell 
tumors in several xenogeneic mouse models, which notably included models of CD19 antigen loss [6]. Herein, we report the translational development and validation of BAFF-R CAR $T$ cells produced under current good manufacturing practices (cGMP) intended for use in a first-in-human Phase 1 trial for BAFF-R-positive relapsed/refractory (r/r) B-ALL.

\section{Methods}

CAR T-cells-BAFF-R CAR T cells were produced from peripheral blood mononuclear cells of healthy donors provided by the Michael Amini Transfusion Medicine Center at City of Hope (IRB: 15283) following two previously established protocols: (1) Research-grade CAR T cells [6] were produced from activated naïve $\mathrm{T}$ cells $\left(\mathrm{T}_{\mathrm{N}}\right)$, transfected at $\mathrm{MOI}=1$, and FACS enriched for CAR-positive $\mathrm{T}$ cells ( $\geq 95 \%)$. (2) cGMP-grade CAR T cells [11] were produced from CliniMACS-isolated early stage $\mathrm{T}$ cells $\left(\mathrm{T}_{\mathrm{N} / \mathrm{MEM}}\right)$, activated, and transfected with the clinical vector at $\mathrm{MOI}=0.5-2$. Each batch of isolated donor $\mathrm{T}$ cells were divided into two aliquots: (1) CAR T-cell production; and (2) non-transduced T-cell controls (cultured and expanded in parallel to CAR T cells).

In vitro assays-Malignant human B-cell lines (Raji, Nalm-6, and Z-138) were purchased from the American Type Culture Collection or Deutsche Sammlung von Mikroorganismen und Zellkulturen GmbH. Modified cell lines (Nalm-6-BAFF-R-KO and Nalm-6-CD19-KO) were previously developed with CRISPR technology [6]. Cytotoxic $T$ lymphocyte (CTL) assay: Chromium-51 $\left({ }^{51} \mathrm{Cr}\right)$ release was used to calculate specific lysis of tumor cells by CAR $\mathrm{T}$ cells as previously described [6]. Briefly, ${ }^{51} \mathrm{Cr}$ labeled target cells were coincubated with CAR T cells. Released ${ }^{51} \mathrm{Cr}$ was detected in clarified supernatant by gamma counter and calculated as a percentage of maximum release. Statistics: mean \pm SD of triplicate samples from a single T-cell donor shown; paired Student's $t$ test of experimental versus controls; experiment repeated with at least three different donor T cells. Degranulation and cytokine release assay: FACS analysis of CD107a-positive (degranulated) CAR T cells and INF gamma release by CAR T cells in response to tumor were assessed as previously described [6].

In vivo modeling - NOD scid gamma (NSG) mice were purchased from The Jackson Laboratory and maintained at the Animal Resource Center of City of Hope in accordance to Institutional Animal Care and Use Committee guidelines (IACUC: 15020). NSG mice were challenged (IV) with previously established, luciferase-expressing tumor models followed by treatment with BAFF-R CAR T cells [6]. Tumor progression was monitored by bioluminescent imagining techniques. Briefly, $n=5$ mice per group were challenged; minimal lethal dose and CAR infusion day in this study were $5 \times 10^{4} \mathrm{Z}-138,7 \mathrm{~d}$; and $0.2 \times 10^{6} \mathrm{Nalm}-6$-CD19$\mathrm{KO}, 10 \mathrm{~d}$. A single infusion of $1-2 \times 10^{6}$ BAFF-R CAR T cells were administered (IV). Survival data are reported in Kaplan-Meier plots and analyzed by log-rank tests.

\section{Results}

We elected to employ a proven clinical development strategy already in use for CAR T-cell production for patients at City of Hope [11-13]. To create the clinical-grade vector BAFF$\mathrm{R}: 4-1 \mathrm{BB}: \zeta / E G F R t$, the BAFF-R-targeting single-chain variable fragment ( $\mathrm{scFv}$ ) [10] was cloned into a second-generation pHIV7 clinical lentiviral vector backbone (Fig. 1a), containing the $4-1 \mathrm{BB}$ and $\mathrm{CD} 3 \zeta$ motifs, a mutant human IgG4 Fc hinge and CD3 extracellular motif and a truncated EGFR (EGFRt) extracellular motif (see Supplementary Table 1). The latter replaces the GFP tracker from the prototype vector (BAFF-R:4-1BB:ל/GFP in a pLenti7.3/v5-DEST lentiviral vector backbone), and can be used as a suicide switch to mitigate cytokine release syndrome (CRS) caused by over-activated CAR T cells [14]. Following the researchgrade CAR production protocol (Fig. 1b), the prototype and clinic-ready (clinical vector used in research-grade production) BAFF-R CAR T cells were produced as previously described [15] for a head-to-head in vitro and in vivo comparison to verify that CAR $\mathrm{T}$ cells produced using the two vectors were equivalent. The research-grade production run yielded $\geq 90 \%$ enriched naïve $T$ cell $\left(\mathrm{T}_{\mathrm{N}}\right)$-derived prototype or clinic-ready CAR T cells, measured by FACS analysis of CD3 and tracker (GFP or EGFRt), respectively, and equivalent expansion rates were observed (Supplementary Figure S1a).

We compared specific cytotoxicity of both CD4 and CD8 $\mathrm{T}_{\mathrm{N}}$-enriched CAR $\mathrm{T}$ cells produced using clinical vector

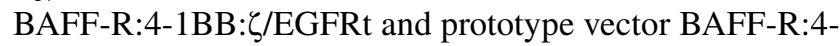

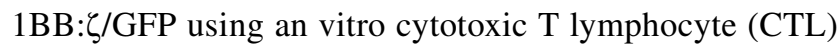
assay [15] in a panel of chromium-51 labeled target malignant B-cell lines including Nalm-6 B-ALL (Fig. 1c). In all tumor models and at varying effector to target ratios, BAFF-

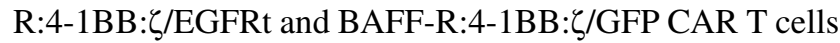
showed similar in vitro activity. Similarly, CAR T cells generated using the two BAFF-R vectors were compared in an established, benchmark B-cell lymphoma tumor model, Z-138 (Fig. 1d). Tumor bearing mice, randomized prior to a single CAR T-cell infusion, were monitored by bioluminescent imaging of luciferase-expressing Z-138 tumors as previously described [15]. Rapid tumor clearance was observed in both the prototype and clinic-ready BAFF-R CAR treated mice. Mice in these treated groups also demonstrate comparable and significant tumor free survival compared to controls (Fig. 1e). Together, these results show that the BAFF$\mathrm{R}: 4-1 \mathrm{BB}: \zeta /$ EGFRt clinical-grade vector-generated CAR T 
Fig. 1 Prototype BAFF-R CAR translated to clinic-ready CAR with equivalent potency. a Diagram depicts BAFF-R scFv from research prototype vector (upper) engineered onto clinical vector (lower). Clinical vector was used previously in FDAapproved CD19 CAR T-cell clinical trials. Notable modifications found on the clinical vector include the 4-1BB and CD3 $\zeta$ motifs, a mutant human IgG4 hinge, with $\mathrm{CD} 3$ and truncated EGFRt extracellular motifs expressed via T2A sequence. b Timeline outlines the critical steps in research-grade CAR T-cell production from naïve $\mathrm{T}$ cell $\left(\mathrm{T}_{\mathrm{N}}\right)$ with CAR-positive T-cell enrichment. CAR T cells in Fig. 1 were produced according to this protocol. $\mathbf{c}$ Graph of calculated specific cytotoxicity following a cytotoxic T lymphocyte assay of CD4 or CD8 $\mathrm{T}_{\mathrm{N}}$ BAFF-R CARs against various B-cell malignancies. Prototype or clinic-ready CAR T cells (effectors) were coincubated with ${ }^{51} \mathrm{Cr}$ labeled B-cell tumors (target) at indicated effector to target ratios. Non-transduced $\mathrm{T}$ cells were used as controls. Two-way ANOVA and multiple comparisons test: $* * P<0.01$ versus non-CAR control. d Bioluminescent imaging shows Z-138 (MCL) in vivo luciferase-expressing, tumor model following treatment with BAFF-R CAR T cells. Mice challenged with tumors at day 0 were randomized and treated with a single infusion of either $1 \times 10^{6}$ prototype or clinic-ready BAFF-R CAR T cells at day 7. Non-transduced T cell or PBS was used as controls. e Mice were monitored for up to 60 days depicted on the survival curve. Log-rank test: $* * P<0.01$ Clinic-ready and Prototype BAFF-R-CAR versus controls
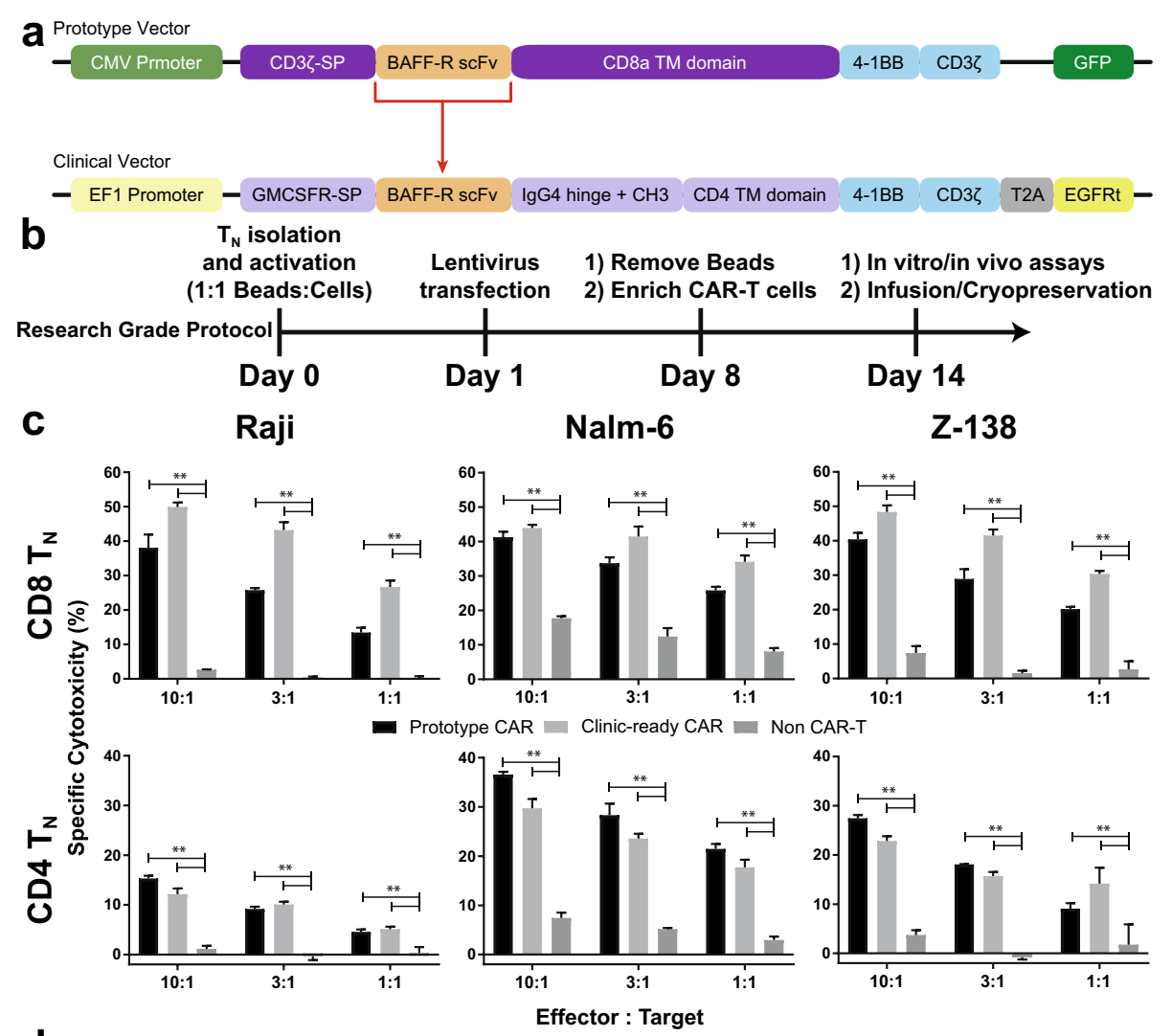

d

Z-138 (MCL)

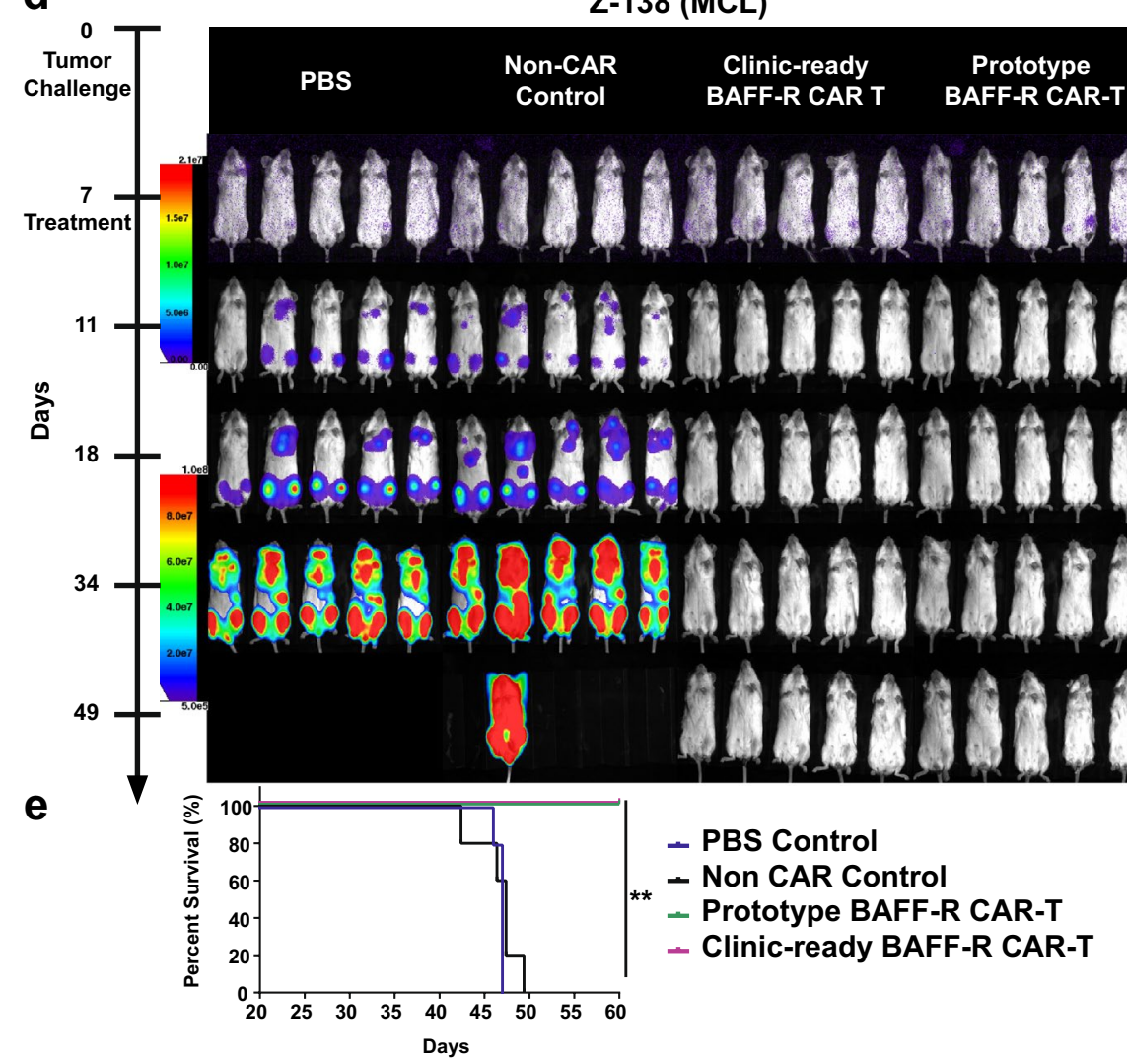


a $\mathrm{T}_{\mathrm{N} / \mathrm{MEM}}$ isolation
and activation
(3:1 Beads:Cells) GMP Protocol

Day 0

b

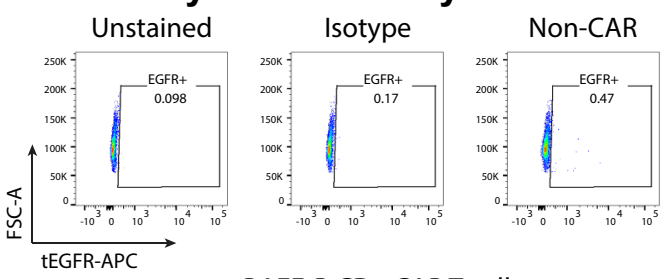

C
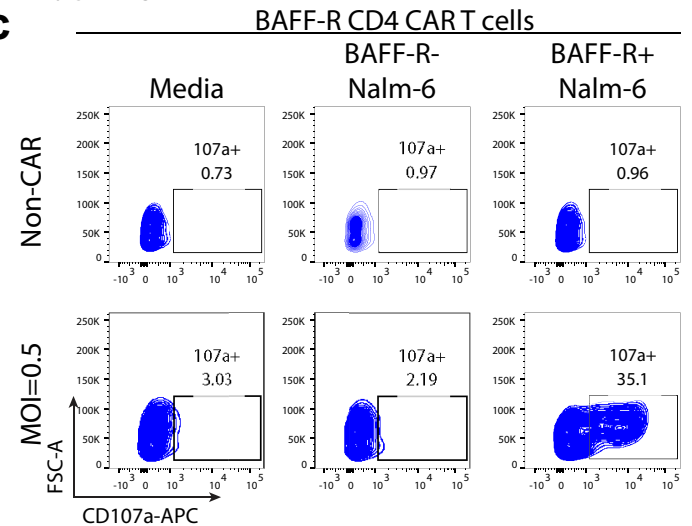

d

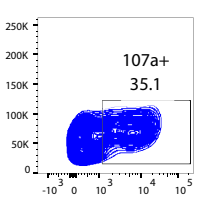

Nalm-6-CD19KO (ALL)

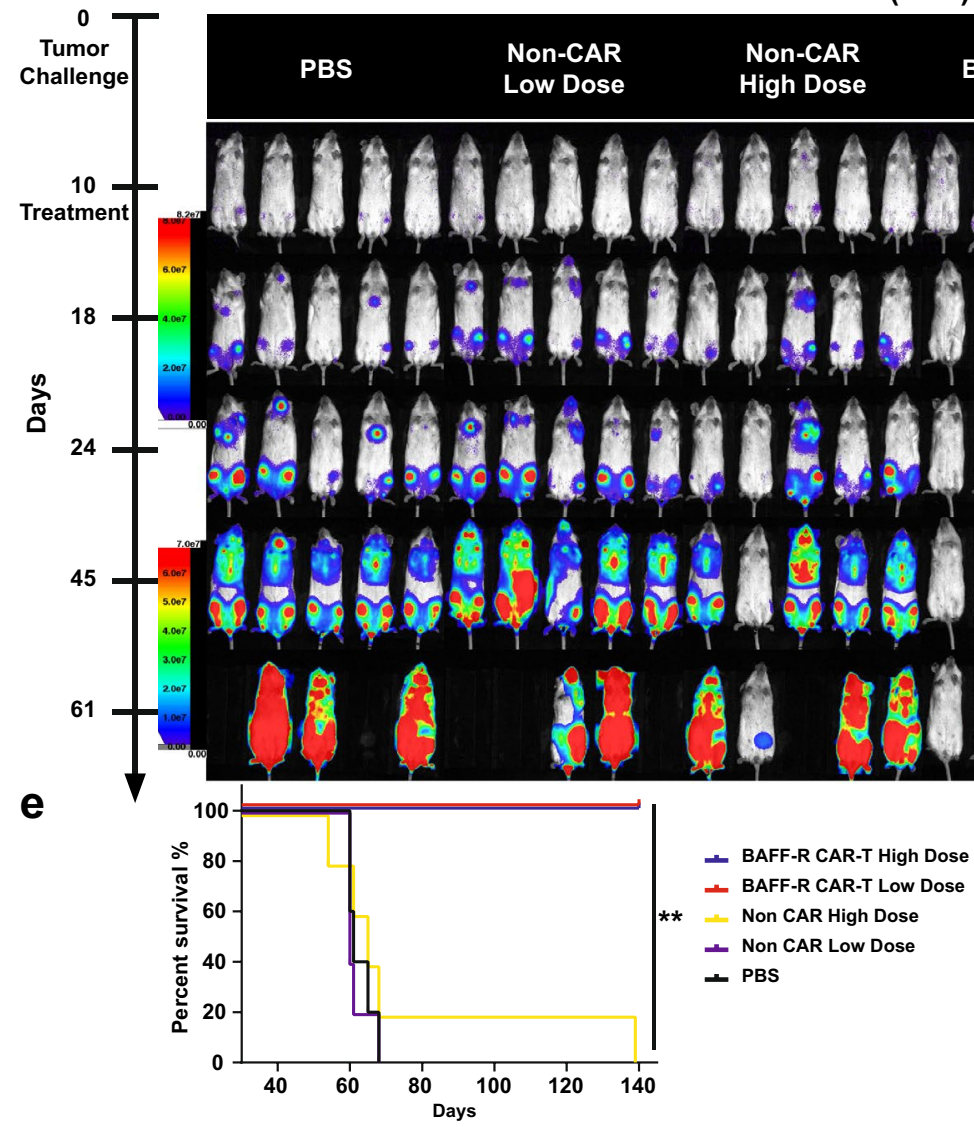

1) Release testing

2) In vivo assay

3) Infusion/Cryopreservation

\section{Day 8 Day 14}
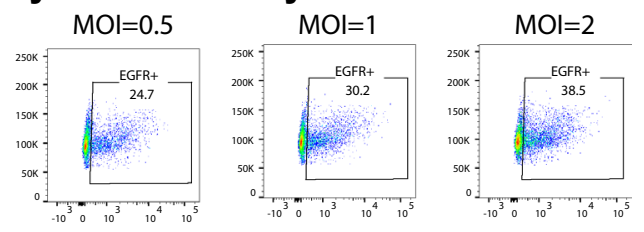
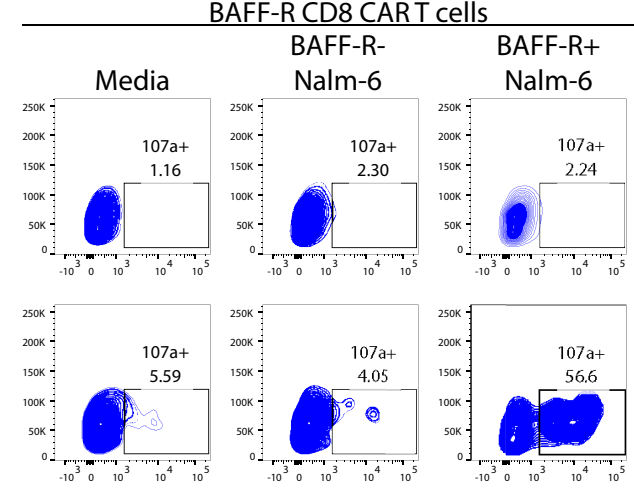

ells 
4Fig. 2 Pilot production of BAFF-R CAR T cells via GMP protocol and release tests. a Timeline outlines the critical steps in cGMP CAR $\mathrm{T}$-cell production from early stage $\mathrm{T}$ cell $\left(\mathrm{T}_{\mathrm{N} / \mathrm{MEM}}\right)$ with FDA required release testing. CAR $\mathrm{T}$ cells in Fig. 2 were produced according to this protocol. b FACS plots show BAFF-R CAR-positive T cell as measured by EGFRt following transfection at various MOIs. CliniMACS isolated $\mathrm{T}_{\mathrm{N} / \mathrm{MEM}}$ cells were transfected at various MOIs and assessed for desired transfection profile, potency, and release requirements. c FACS plots of BAFF-R CAR T-cell functional potency as measured by a CD107a degranulation assay. CD4 or CD8 BAFF-R CAR T cells were coincubated with either BAFF-R-positive or negative Nalm-6 B-ALL line. d Bioluminescent imaging shows Nalm-6CD19KO (ALL) in vivo luciferase-expressing tumor model following treatment with BAFF-R CAR T cells. Mice challenged with tumors at day 0 were randomized and treated with a single infusion of low dose $2.8 \times 10^{6} \mathrm{~T}_{\mathrm{N} / \mathrm{MEM}}$ or high dose $5.6 \times 10^{6} \mathrm{~T}_{\mathrm{N} / \mathrm{MEM}}$, which yielded $1 \times 10^{6}$ and $2 \times 10^{6}$ BAFF-R CAR T cells, respectively, at day 10 . Controls were non-transduced $\mathrm{T}$ cell or PBS. e Mice were monitored for up to 140 days depicted on the survival curve. Log-rank test: $* * P<0.01$ GMP BAFF-R-CAR High and Low Dose versus controls

cells are functionally equivalent to those produced by the BAFF-R:4-1BB:ל/GFP prototype vector. We could then reasonably proceed to further preclinical development.

We next evaluated cGMP protocols for lentiviral vector production and CAR $\mathrm{T}$ cell manufacture with the aim of completing FDA-mandated investigational new drug (IND)enabling studies following the procedure outlined in Fig. 2a. We therefore set out to optimize BAFF-R CAR T-cell production under several key criteria including: minimum viral load; maximized transduction efficiency, functional potency; and passing FDA required release testing.

The City of Hope Biologics \& Cellular GMP Manufacturing Center produced BAFF-R:4-1BB:ל/EGFRt clinical vector under cGMP conditions. Transfection of $\mathrm{T}_{\mathrm{N} / \mathrm{MEM}}$ cells obtained from healthy donors [Michael Amini Transfusion Medicine Center at the City of Hope (IRB: 15283)] was evaluated at three multiplicities of infection (MOI), 0.5, 1, and 2 (Fig. 2b). All three MOIs produced viable CAR T cells with equivalent growth and expansion rates (Supplementary Figure S1b), and transduction efficiency measured by FACS analysis of EGFRt were equivalent for all MOIs. Maximized functional potency was confirmed by BAFF-R specific activation of BAFF-R CAR T cells, measured by CD107a degranulation marker following incubation with target cell lines (Fig. 2c, Supplementary Figure S2) as previously described [15]. Functional potency at $\mathrm{MOI}=0.5$ was similar to $\mathrm{MOI}=1$ or 2 . Furthermore, the BAFF-R-induced CAR T cell INF- $\gamma$ release did not vary significantly between MOIs (Supplemental Figure S3). Subsequent batches of BAFF-R CAR T cells were produced with $\mathrm{MOI}=0.5$ transfection and underwent FDA required release testing.

Three donor leukapheresis products were successfully used to generate BAFF-R CAR T cells following the GMP protocol derived from a successful production strategy that implements CliniMACS automation for T-cell isolation
[11]. The original manufacturing strategy was developed and implemented at City of Hope and produces CAR T cells from early stage $\mathrm{T}$ cells $\left(\mathrm{T}_{\mathrm{N} / \mathrm{MEM}}\right)$ consisting of naïve, memory-like stem, and central memory $T$ cells. Each batch of cells were closely monitored during the transfection, expansion, and activation stages. Each exceeded the minimum requirements of qualification release testing set forth by the FDA, which included viability ( $\geq 70 \%)$, identity measured by CD3 ( $\geq 80 \%)$, transduction efficiency and CAR expression measured by EGFRt ( $\geq 10 \%)$, WPRE copy insertion ( $\leq 5$ copies/cell), and VSVG copy insertion $(\leq 2.5$ copies/50 ng genomic DNA) (Table 1).

Lastly, we repeated an in vivo study to confirm the efficacy of the BAFF-R:4-1BB: $/ / E G F R t$ CAR T cells produced under the GMP protocol, as the research and GMP production strategies differed in the specific T-cell isolation and expansion steps. Specifically, the GMP strategy isolates all early stage $\mathrm{T}$ cells (naïve, memory-like stem, and central memory), whereas the research product was exclusively produced from naïve T cells. Secondly, the CAR T-cell enrichment was omitted in the GMP procedures, yielding a more heterogeneous product consisting of $25-35 \%$ CAR T cells. Therefore, experimental group dosing in the in vivo Nalm-6 ALL tumor model study is denoted as low dose $\left(2.8 \times 10^{6}\right.$ $\mathrm{T}$ cell yielding an effective $1 \times 10^{6} \mathrm{BAFF}-\mathrm{R}$ CAR T cells) or high dose $\left(5.6 \times 10^{6} \mathrm{~T}\right.$ cell yielding an effective $2 \times 10^{6}$ BAFF-R CAR T cells) (Fig. 2d). Remarkably, mice treated with either a low or high dose of cGMP BAFF-R CAR T cells demonstrated rapid tumor clearance and tumor-free survival up to 140 days after tumor challenge (Fig. 2e).

\section{Discussion}

Rapid translation of BAFF-R CAR T-cell therapy to clinical application is warranted because it is a potentially promising immunotherapy, especially for antigen-loss r/r B-ALL following CD19-targeted treatments. To expedite this process we used a proven platform for CAR gene delivery and CAR $\mathrm{T}$-cell production in order to ensure reliability and rapid translation into an upcoming first-in-human clinical trial. Notably, the original prototype BAFF-R CAR T cells were produced with a highly selective cell isolation and enrichment protocol that yielded a nearly homogeneous (>90\%) population BAFF-R CAR naïve T cells. This research protocol modeled the ideal early stage $\mathrm{T}$ cell for CAR T-cell production and ensured reproducibility of results particularly for in vivo dosing. However, it would be challenging to reliably produce and deliver enriched naïve CAR T cells from patients in the clinic. The chosen platform seeks to balance proven efficacy seen in the preclinical studies with FDAapproved, GMP protocols. BAFF-R CAR T cells intended for patients will therefore include all early stage $\mathrm{T}$ cells 
Table 1 Qualification release testing

\begin{tabular}{|c|c|c|c|c|c|c|}
\hline Culture condition & MOI & Viability (\%) & $\begin{array}{l}\text { Identity (CD3) } \\
(\%)\end{array}$ & $\begin{array}{l}\text { Transfection efficiency } \\
\text { (tEGFR) }(\%)\end{array}$ & $\begin{array}{l}\text { WPRE (Copy Num- } \\
\text { ber/Cell) }\end{array}$ & $\begin{array}{l}\text { VSVG (Copy } \\
\text { Number/50 ng } \\
\text { gDNA) }\end{array}$ \\
\hline \multicolumn{7}{|l|}{ HD409 (Run 1) } \\
\hline Plate & Mock & 87 & 99.9 & 0.47 & 0.0023648 & $<2.5$ copies \\
\hline Plate & 0.5 & 86 & 99.9 & 24.7 & 0.8429023 & $<2.5$ copies \\
\hline Plate & 1 & 84 & 99.9 & 30.2 & 0.9550843 & $<2.5$ copies \\
\hline Plate & 2 & 86 & 99.9 & 38.5 & 1.2226313 & $<2.5$ copies \\
\hline \multicolumn{7}{|l|}{ HD408 (Run 2) } \\
\hline Bag & Mock & 83 & 99.7 & 0.57 & 0.0046748 & $<2.5$ copies \\
\hline Bag & 0.5 & 79 & 99.8 & 30.9 & 1.2712262 & $<2.5$ copies \\
\hline Plate & Mock & 85 & 99.7 & 0.68 & 0.0061125 & $<2.5$ copies \\
\hline Plate & 0.5 & 81 & 99.7 & 35.5 & 0.9591207 & $<2.5$ copies \\
\hline \multicolumn{7}{|l|}{ HD562 (Run 3) } \\
\hline Bag & Mock & 94 & 99.8 & 0.85 & 0.002598089 & $<2.5$ copies \\
\hline Bag & 0.5 & 91 & 99.8 & 24.5 & 0.556451478 & $<2.5$ copies \\
\hline
\end{tabular}

following the $\mathrm{T}_{\mathrm{N} / \mathrm{MEM}}$ GMP protocol [13]. Although we are not enriching BAFF-R CAR-positive cells prior to infusion, the cell product has consistently been 24-35\% CAR-positive; exceeding the FDA requirements of $>10 \%$.

Collectively, the data fully support the initiation of a first-in-human Phase 1 clinical trial to examine the safety of BAFF-R CAR T cells, particularly given the urgent need to address r/r B-ALL following CD19-targeted immunotherapy. We expect a comparable safety profile of our BAFF-R CAR $T$ cells to other CARs in clinical use, and would also expect to observe efficacy based on the strong preclinical results.

Acknowledgements Research reported in this publication included work performed in the Analytical Cytometry Core, and Small Animal Imaging Core supported by the National Cancer Institute of the NIH under Award Number P30CA033572. The content is solely the responsibility of the authors and does not necessarily represent the official views of the NIH. Lentiviral materials and support was for this study was contracted to the Biologics \& Cellular GMP Manufacturing Center at City of Hope. Funding: We are grateful for the support from the Toni Stephenson Lymphoma Center at Beckman Research Institute of City of Hope. The study was also supported by the Leukemia and Lymphoma Society (LLS): Translational Research Program (TRP 6540-18; PI: L.W.K.), Mantle Cell Lymphoma Research Initiative (MCL 7000-18; PI: L.W.K; the NIH/NCI (SPORE 2P50CA107399; PIs: S.J.F. and L.W.K.; 1R21CA223141; PI: H.Q.); the Department of Defense (CA170783; PI: L.W.K.).

Author Contributions $\mathrm{ZD}, \mathrm{BH}, \mathrm{TZ}$, and $\mathrm{WC}$ conducted in vitro and in vivo experiments. WAC and DLS contributed to data analysis and manuscript preparation. SJF and LWK oversaw the project including data analysis and manuscript writing. HQ and XW designed and initiated the project, oversaw experiments, analyzed data, and wrote the manuscript.

Data and materials availability Data and materials produced in this study are protected by City of Hope intellectual property patents but will remain available to qualified investigators at other research organization by establishing a Material Transfer Agreement (MTA). MTA requests should be directed to the corresponding author.

\section{Compliance with ethical standards}

Conflict of interest LWK and HQ have license agreements with and receive research support from Pepromene Bio Inc. All other authors declare no competing financial interests.

Open Access This article is licensed under a Creative Commons Attribution 4.0 International License, which permits use, sharing, adaptation, distribution and reproduction in any medium or format, as long as you give appropriate credit to the original author(s) and the source, provide a link to the Creative Commons licence, and indicate if changes were made. The images or other third party material in this article are included in the article's Creative Commons licence, unless indicated otherwise in a credit line to the material. If material is not included in the article's Creative Commons licence and your intended use is not permitted by statutory regulation or exceeds the permitted use, you will need to obtain permission directly from the copyright holder. To view a copy of this licence, visit http://creativecommons.org/licenses/by/4.0/.

\section{References}

1. Terwilliger T, Abdul-Hay M (2017) Acute lymphoblastic leukemia: a comprehensive review and 2017 update. Blood Cancer J 7:e577. https://doi.org/10.1038/bcj.2017.53

2. Jabbour E, O'Brien S, Konopleva M, Kantarjian H (2015) New insights into the pathophysiology and therapy of adult acute lymphoblastic leukemia. Cancer 121:2517-2528. https://doi. org/10.1002/cncr.29383

3. Grupp SA, Laetsch TW, Buechner J et al (2016) Analysis of a global registration trial of the efficacy and safety of CTL019 in pediatric and young adults with relapsed/refractory acute lymphoblastic leukemia (ALL). Blood 128:221 
4. Maude SL, Laetsch TW, Buechner J et al (2018) Tisagenlecleucel in children and young adults with B-cell lymphoblastic leukemia. New Engl J Med 378:439-448. https://doi.org/10.1056/NEJMo a1709866

5. Ruella M, Barrett DM, Kenderian SS et al (2016) Dual CD19 and CD123 targeting prevents antigen-loss relapses after CD19directed immunotherapies. J Clin Investig 126:3814-3826. https ://doi.org/10.1172/JCI87366

6. Qin H, Dong Z, Wang X et al (2019) CAR T cells targeting BAFF-R can overcome CD19 antigen loss in B cell malignancies. Science translational medicine. 11:eaaw9414. https://doi. org/10.1126/scitranslmed.aaw9414

7. Treml JF, Hao Y, Stadanlick JE, Cancro MP (2009) The BLyS family: toward a molecular understanding of B cell homeostasis. Cell Biochem Biophys 53:1-16. https://doi.org/10.1007/s1201 3-008-9036-1

8. Rodig SJ, Shahsafaei A, Li B, Mackay CR, Dorfman DM (2005) BAFF-R, the major B cell-activating factor receptor, is expressed on most mature B cells and B-cell lymphoproliferative disorders. Hum Pathol 36:1113-1119. https://doi.org/10.1016/j.humpa th.2005.08.005

9. Novak AJ, Grote DM, Stenson M et al (2004) Expression of BLyS and its receptors in B-cell non-Hodgkin lymphoma: correlation with disease activity and patient outcome. Blood 104:2247-2253. https://doi.org/10.1182/blood-2004-02-0762

10. Qin H, Wei G, Sakamaki I et al (2018) Novel BAFF-receptor antibody to natively folded recombinant protein eliminates drugresistant human B-cell malignancies in vivo. Clin Cancer Res 24:1114-1123. https://doi.org/10.1158/1078-0432.CCR-17-1193
11. Wang X, Popplewell LL, Wagner JR et al (2016) Phase 1 studies of central memory-derived CD19 CAR T-cell therapy following autologous HSCT in patients with B-cell NHL. Blood 127:2980 2990. https://doi.org/10.1182/blood-2015-12-686725

12. Wang X, Berger C, Wong CW, Forman SJ, Riddell SR, Jensen MC (2011) Engraftment of human central memory-derived effector $\mathrm{CD}^{+} \mathrm{T}$ cells in immunodeficient mice. Blood 117:1888-1898. https://doi.org/10.1182/blood-2010-10-310599

13. Wang X, Naranjo A, Brown CE et al (2012) Phenotypic and functional attributes of lentivirus-modified CD19-specific human $\mathrm{CD}^{+}$central memory $\mathrm{T}$ cells manufactured at clinical scale. $\mathrm{J}$ Immunother 35:689-701. https://doi.org/10.1097/CJI.0b013e3182 $70 \mathrm{dec} 7$

14. Jones BS, Lamb LS, Goldman F, Di Stasi A (2014) Improving the safety of cell therapy products by suicide gene transfer. Front Pharmacol 5:254. https://doi.org/10.3389/fphar.2014.00254

15. Qin H, Dong Z, Wang X et al (2019) CAR T cells targeting BAFF$\mathrm{R}$ can overcome CD19 antigen loss in B cell malignancies. Sci Transl Med. https://doi.org/10.1126/scitranslmed.aaw9414

Publisher's Note Springer Nature remains neutral with regard to jurisdictional claims in published maps and institutional affiliations. 